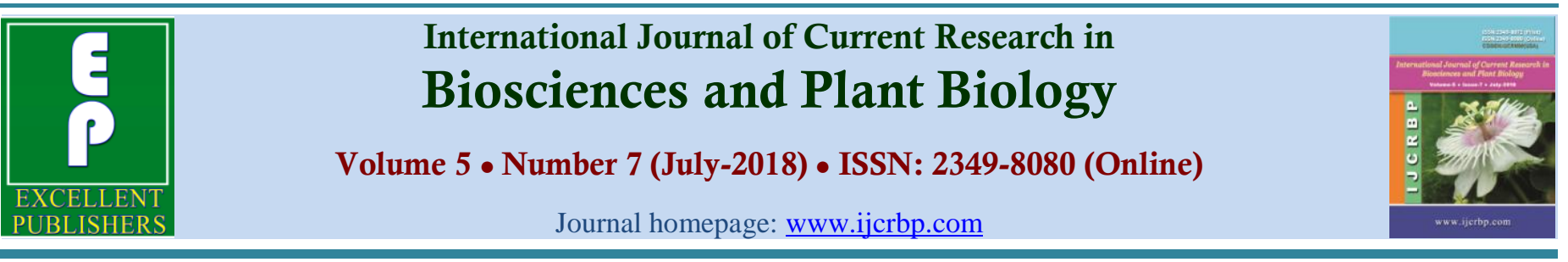

\title{
Open versus Endoscopic Release of Carpal Tunnel Syndrome
}

\author{
Mustafa Elsagair ${ }^{1,3 *}$, Ala Wafa ${ }^{2}$, Wisam Abozaid ${ }^{1,3}$ and Aziz Teeka ${ }^{1,3}$
}

\author{
1Orthopedic Department, Aljazeera Hospital, Misurata, Libya \\ ${ }^{2}$ General Surgery Department, Aljazeera Hospital, Misurata, Libya \\ 3Orthopedic Department, Almahjob General Hospital, Misurata, Libya
}

*Corresponding author.

\begin{tabular}{|c|c|}
\hline Article Info & ABSTRACT \\
\hline $\begin{array}{l}\text { Date of Acceptance: } \\
15 \text { June } 2018\end{array}$ & \multirow{4}{*}{$\begin{array}{l}\text { A total of } 90 \text { hands belonging to } 80 \text { patients were included in the study. They were } \\
\text { mostly female ( } 70) \text { and the rest were male (10). There were } 30 \text { endoscopic releases, } 60 \\
\text { open releases, and } 2 \text { endoscopic converted to open release. There were } 15 \text { hands } \\
\text { complications in } 90 \text { hands. The overall complication rate was } 12.2 \% \text {. Complications } \\
\text { noted were pillar pain, open tendonitis presenting as De Quervain disease or trigger } \\
\text { finger ( } 1 \text { endoscopic surgeries, } 1 \text { open surgeries), infection ( } 1 \text { endoscopic surgeries, } \\
\text { open surgeries), wound adhesion ( } 3 \text { open surgeries), nerve injury ( } 2 \text { open surgery, } \\
\text { endoscopic), complex regional pain syndrome ( } 4 \text { open surgery), and scheduled return } \\
\text { to the operating room (OR) for recurrent, ongoing, or worsening symptoms } \\
\text { endoscopic surgeries, } 5 \text { open surgeries). In carpal tunnel syndrome, endoscopic surgery } \\
\text { was associated with less postoperative pain than open surgery, but the small size of the } \\
\text { benefit and similarity in other outcomes make its cost effectiveness uncertain. There } \\
\text { were } 12 \text { patients (out of } 90) \text { in the surgery group had painful or hypertrophic scar or } \\
\text { pillar pain. Wound adhesion and pillar pain was the only statistically significan } \\
\text { complication found in the study when comparing open with endoscopic carpal tunne } \\
\text { release. This can potentially be prevented in future patients by delaying the removal of } \\
\text { sutures and prolonging the use of a protective dressing in patients who undergo oper } \\
\text { release. There was not a statistically significant increase in overall complications when } \\
\text { using the minimally invasive method of release, which is consistent with existing } \\
\text { literature. }\end{array}$} \\
\hline $\begin{array}{l}\text { Date of Publication: } \\
\text { 06 July } 2018\end{array}$ & \\
\hline Keywords & \\
\hline $\begin{array}{l}\text { Carpal tunnel syndror } \\
\text { Endoscopic release } \\
\text { Open surgery } \\
\text { Pillar pain }\end{array}$ & \\
\hline
\end{tabular}

\section{Introduction}

Carpal tunnel release is one of the most common hand surgeries performed in Libya, done by many subspecialty as orthopedic, general surgery, plastic, and neurosurgery. Depending on surgeon experience and comfort level, surgeries are performed through either the traditional open method or the endoscopic method, single or double port. The advantage of the endoscopic method is faster 
recovery and return to work; however, the endoscopic method requires more expensive equipment and a steeper learning curve for surgeons (Aslani et al., 2012; Assmus et al., 2006; Vasiliadis et al., 2010; Beck et al., 2011). Complications are uncommon but can create unsatisfactory patient experiences because of costly lost workdays and long travel distances to the medical facility. We have performed a prospective, randomized, blinded assessment in a district general hospital and private hospital in order to determine if there was any demonstrable advantage in undertaking either technique independent preoperative and postoperative assessment was undertaken by a hand the rapist who was blinded to the type of treatment.

The theoretical advantages of an endoscopic release are reduced tenderness of the scar, an earlier return of grip strength and an earlier return to work. The perceived disadvantages are an increased risk of nerve damage and questionable efficacy. The technique is also more expensive (Ferdinand and MacLean, 2002). We have therefore compared the endoscopic and open techniques in order to determine any differences in outcome. The purpose of this study was to compare the endoscopic method with the open carpal tunnel release method to determine whether there was an increased complication risk.

\section{Materials and methods}

The study was done of patients who had carpal tunnel surgery performed by orthopedic surgery department of Aljazeera Orthopedic Hospital and Almahjop General Hospital service from May 2017, to March 2018. Most of the surgeries included in the study were performed by a resident or fellow under the supervision of an attending physician. Only primary carpal tunnel releases were included in the study. Exclusion criteria included patients who were operated on by a service section other than the orthopedic surgery service (general surgery or plastic or neurosurgery).

Methods of release were endoscopic, open, or endoscopic converted to open. All but 30 of the completed endoscopic surgeries were performed. The 32 endoscopic surgeries were performed using the single port Agee technique at the distal wrist crease, There were 2 endoscopic converted to open cases that were performed using a single port, proximally-based technique in the midpalm. Endoscopic surgeries converted to open were recorded as open surgeries, 80 patients. 70 patients unilateral carpal tunnel syndrome release is done, Bilateral carpal tunnel done for 10 patient in deferent time of intervention.

\section{Results and complications}

The open carpal tunnel release and scar, and Endoscopic carpal tunnel release are shown in Figs. $1-4$. A total of 90 hands belonging to 80 patients were included in the study, patients included 10 men and 70 women aged from 25 to 70 years (Fig. $5)$. There were 30 endoscopic releases, 60 open releases, and 2 endoscopic converted to open release. There were 15 hands complications in 90 hands. The overall complication rate was $12.2 \%$. The results on the endoscopic vs open surgery complications and re-operative carpal tunnel release are shown in Tables 1 and 2.

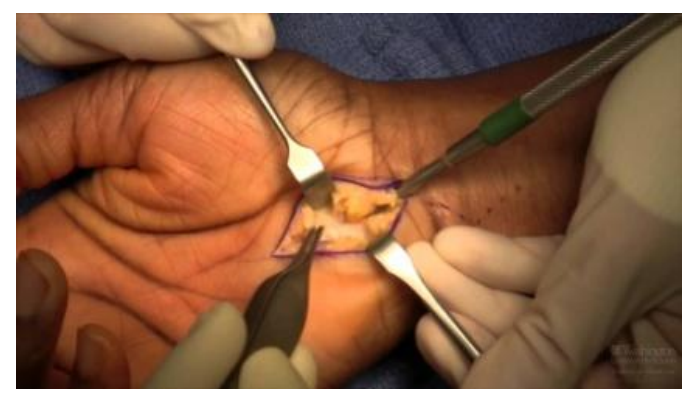

Fig. 1: Open carpal tunnel release.

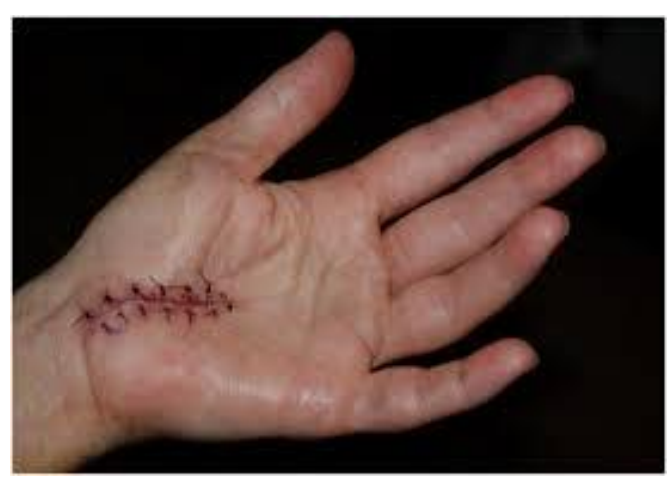

Fig. 2: Open carpal tunnel release scar. 


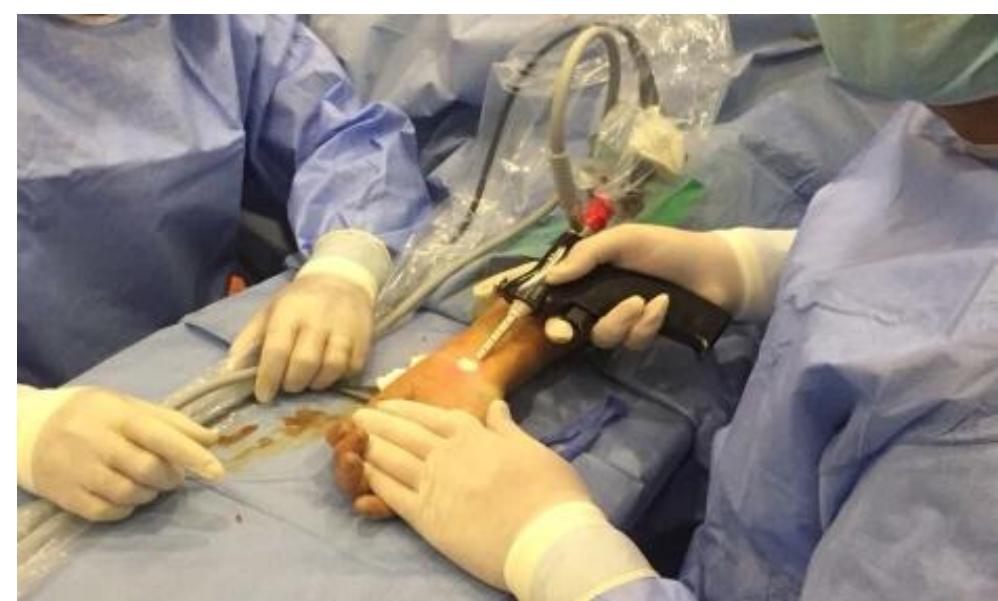

Fig. 3: Endoscopic carpal tunnel release.

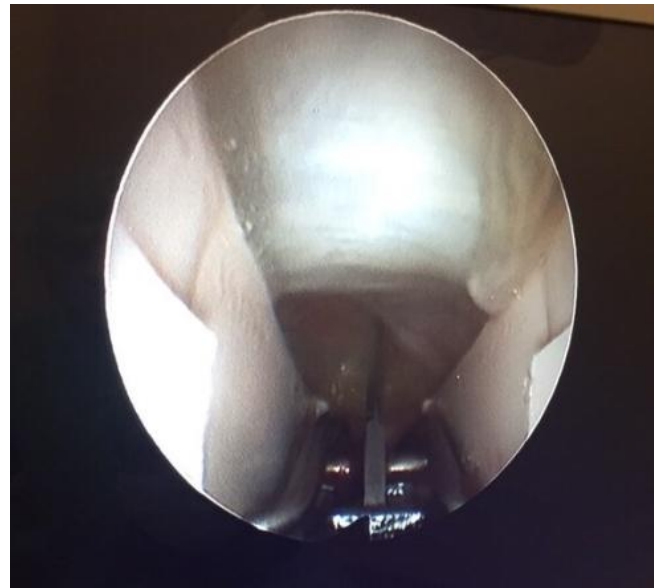

Fig. 4: Endoscopic carpal tunnel release.
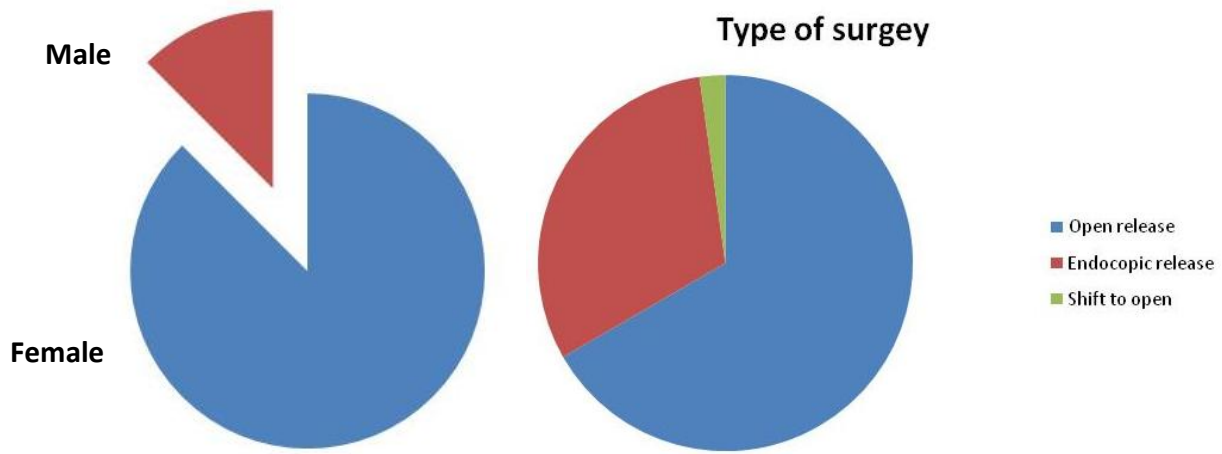

Fig. 5: Carpal tunnel syndrome in male and females and type of surgery performed.

Complications noted were pillar pain 2 endoscopic (10 open tendonitis presenting as De Quervain disease or trigger finger 1 endoscopic surgeries; 1 open surgeries), infection 1 endoscopic surgeries; 3 open surgeries), wound adhesion (3 open surgeries), nerve injury 2 open surgery 1endoscopic, complex regional pain syndrome (4 open surgery), and scheduled returns to the operating room (OR) for recurrent, ongoing, or worsening symptoms (2 endoscopic surgeries; 5 open surgeries) (Fig. 6).

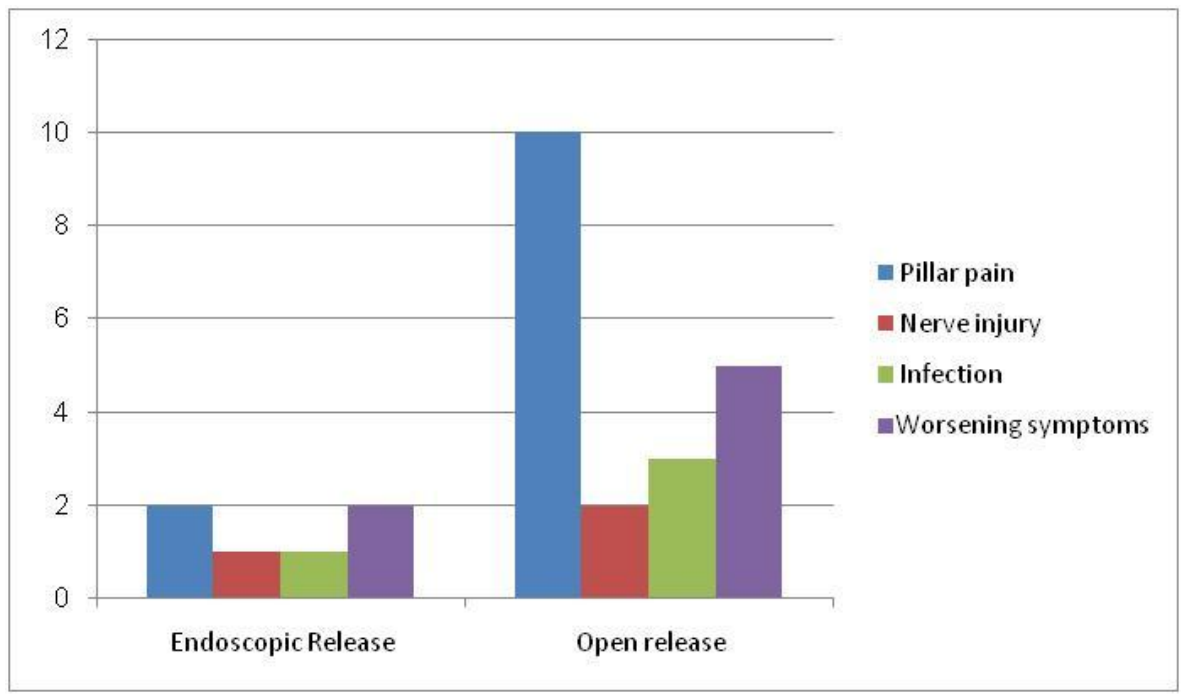

Fig. 6: Complications of endoscopic and open surgeries. 
The study had 4 patients return to the OR for open exploration 1 of these patients went back to the OR based on symptoms consistent with nerve conduction studies that had deteriorated compared with their preoperative studies. One endoscopic case was brought back to the OR for a suspected nerve injury without nerve conduction studies. One endoscopic case was brought back to the OR for a suspected incomplete release. Findings during reoperation included scar adhesions, incomplete release of ligaments, digital nerve injury, and negative explorations.

One hypothenar fat transfers were performed to prevent scar adhesions in cases that had originally been open releases. One of the open cases was endoscopic converted to open cases. One went back to the OR with a suspected nerve injury. Dense adhesions and an injured common digital nerve were identified and repaired. The second converted case that went back to the OR had a suspected, but unconfirmed, nerve injury to the motor branch An early complex regional pain syndrome diagnosis was made in a patient with underlying neuropathy and a preoperative "profound" median neuropathies diagnosis at the wrist with underlying peripheral neuropathy found on nerve conduction studies. The patient experienced an unusual amount of postoperative pain and edema after an uncomplicated open carpal tunnel release.

This was treated with rapid intervention using antiinflammatories and hand therapy. The patient also started a regimen of skin care, edema management, neuroreducation, and contrast baths. Symptoms responded within a week. There were 4 wound complications: 5 in open and 1 in endoscopic surgeries. Total wound complications were equally split between patients with and without diabetes. Infection and adhesion were noted. Sutures were removed an average of 10-15 days after surgery in the patients whose wounds broke down. There was no statistically significant difference in the overall complication rate in our study when comparing endoscopic with open carpal tunnel release or when comparing the risk of postoperative tendonitis, wound infection, or return to the OR.

\section{Discussion}

Carpal tunnel syndrome is most broadly defined as a condition characterized by an abnormality of median nerve function due to compression of the nerve within the carpal canal (Aroori and Spence, 2008). The median nerve is compressed when the space available to it is decreased within the finite volume of the carpal canal. Conditions that cause synovial swelling are known to be associated with carpal tunnel syndrome. Pregnancy and rheumatoid arthritis are two well-known examples (AAOS, 2016; Osterman et al., 2012).

Intrinsic abnormalities of the median nerve itself may also act to lower the threshold for symptomatic compression. Pressures within the carpal canal that might not otherwise cause symptoms of carpal tunnel syndrome may do so if the nerve is rendered particularly sensitive to pressure by some other disease or condition. A common example of this is diabetes mellitus, Carpal tunnel syndrome was documented by James Paget in mid-19th century in reference to a distal radius fracture (Paget, 1853). It is the most common peripheral nerve compression, with an incidence ranging from 1 to 3 cases per 1,000 subjects per year and a prevalence of 50 cases per 1,000 subjects per year in U.S.A. (Bickel, 2010). The endoscopic method of release was first introduced in 1989 by Okutsu and colleagues. Open method is the most kind of intervention in Libya.

The minimally invasive procedure was designed to preserve the overlying skin and fascia, promoting an earlier return to work and daily activities. This is particularly relevant for manual workers who desire rapid return of grip strength. Multiple published reports have found more rapid recovery based on a reduction in scar tenderness, increase in grip strength, or return to work (Malhotra et al., 2007; Vasiliadis et al., 2010; Sabesan et al., 2012; Larsen et al., 2013). Patients seem to have equivalent results over the long term, ranging from 3 months to 10 years. Return to work was not valuated in this study, because many 
patients were either retired or not working steadily.

The endoscopic method was criticized after its introduction due to its potential increase in major structural injury to the median nerve, ulnar nerve, palmar arch, ulnar artery, or flexor tendons (Kohanzadeh et al., 2012). A meta-analysis found improved outcomes but a statistically significant higher complication rate in open, compared with endoscpoic release (13\% in endoscopic vs $16 \%$ in open). Referral patterns have found iatrogenic nerve injury in patients referred by surgeons without formal hand fellowship training (Azari et al., 2007). There is a wide variety of background training for surgeons who may offer carpal tunnel release, including plastic surgery, orthopedics, general surgery, and neurosurgery.

Researchers who conducted similar study confirmed one common digital nerve injury in an endoscopic converted to open technique. The endoscopic method has been found to have a higher rate of reversible nerve injury (neuropraxia) compared with the open technique (Vasiliadis et al., 2015). The study results found a higher rate of wound adhesion. More frequent wound site complications, particularly infection, hypertrophic scar, and scar tenderness have been noted using the open method. This is probably due to the deeper and slightly larger incision used for the open method compared with the smaller and shallower incisions used for the endoscopic release.

\section{Conclusion}

Wound adhesion and pillar pain was the only statistically significant complication found in the study when comparing open with endoscopic carpal tunnel release. This can potentially be prevented in future patients by delaying the removal of sutures and prolonging the use of a protective dressing in patients who undergo open release. There was not a statistically significant increase in overall complications when using the minimally invasive method of release, which is consistent with existing literature.

\section{Conflict of interest statement}

Authors declare that they have no conflict of interest.

\section{References}

AAOS (American Academy of Orthopaedic Surgeons), 2016. Management of Carpal Tunnel Syndrome Evidence-Based Clinical Practice Guideline. February 29, 2016.

Aroori, S., Spence, R. A., 2008. Carpal tunnel syndrome. Ulster Med. J. 77(1), 6-17.

Aslani, H. R., Alizadeh, K., Eajazi, A., et al. 2012. Comparison of carpal tunnel release with three different techniques. Clin. Neurol. Neurosurg. 114(7), 965-968.

Assmus, H., Dombert, T., Staub, F., 2006. Reoperations for CTS because of recurrence or for correction [article in German]. Handchir Mikrochir PlastChir. 38(5), 306-311.

Azari, K. K., Spiess, A. M., Buterbaugh, G. A., Imbriglia, J. E., 2007. Major nerve injuries associated with carpal tunnel release. Plast. Reconstr. Surg. 119(6), 1977-1978.

Beck, J. D., Deegan, J. H., Rhoades, D., Klena, J. C., 2011. Results of endoscopic carpal tunnel release relative to surgeon experience with the Agee technique. J. Hand Surg. Am. 36(1), 61-64.

Bickel, K., 2010. Carpal tunnel syndrome. J. Hand Surg. 35A, 147-152.

Ferdinand, R. D., MacLean, J. G., 2002. Endoscopic versus open carpal tunnel release in bilateral carpal tunnel syndrome. A prospective, randomised, blinded assessment. J. Bone Joint Surg. [Br]. 84-B, 375-379.

Kohanzadeh, S., Herrera, F. A., Dobke, M., 2012. Outcomes of open and endoscopic carpal tunnel release: A meta-analysis. Hand (NY). 7(3), 247251.

Larsen, M. B., Sørensen, A. I., Crone, K. L., Weis, T., Boeckstyns, M. E., 2013. Carpal tunnel release: A randomized comparison of three surgical methods. J. Hand Surg. Eur. 38(6), 646-650.

Malhotra, R., Kiran, E. K., Dua, A., Mallinath, S. G., Bhan, S., 2007. Endoscopic versus open 
carpal tunnel release: A short-term comparative study. Indian J. Orthop. 41(1), 57-61.

Okutsu, I., Ninomiya, S., Takatori, Y., Ugawa, Y., 1989. Endoscopic management of carpal tunnel syndrome. Arthroscopy. 5(1), 11-18.

Osterman, M., Ilyas, A. M., Matzon, J. L., 2012. Carpal tunnel syndrome in pregnancy. Orthopedic Clinics of North America. 43(4), 515-520.

Paget, J., 1853. Lectures on Surgical Pathology Delivered at the Royal College of Surgeons of England. London, England: Longman, Green, Brown, and Longmans.

Sabesan, V. J., Pedrotty, D., Urbaniak, J. R.,
Aldridge, J. M., 2012.. An evidence-based review of a single surgeon's experience with endoscopic carpal tunnel release. J. Surg. Orthop. Adv. 21(3), 117-121.

Vasiliadis, H. S., Nikolakopoulou, A., Shrier, I., Lunn, M. P., Brassington, R., Scholten, R. J. P., et al. 2015. Endoscopic and open release similarly safe for the treatment of carpal tunnel syndrome. A systematic review and metaanalysis. PLoS One. 10(12), e0143683.

Vasiliadis, H. S., Xenakis, T. A., Mitsionis, G., Paschos, N., Georgoulis, A., 2010. Endoscopic versus open carpal tunnel release. Arthroscopy. 26(1), 26-33.

\section{How to cite this article:}

Elsagair, M., Wafa, A., Abozaid, W., Teeka, A., 2018. Open versus endoscopic release of carpal tunnel syndrome. Int. J. Curr. Res. Biosci. Plant Biol. 5(7), 37-42.

doi: https://doi.org/10.20546/ijcrbp.2018.507.005 